\title{
Environmental evaluation of alternative chemicals to methyl bromide for fumigation of quarantine pests in transit
}

\author{
A. G. S. Cuthbertson - K. Mills • T. Wonter-Smith • \\ L. F. Blackburn · J. J. Mathers $\cdot$ P. Northing
}

Received: 31 August 2011/Revised: 29 April 2012/Accepted: 28 November 2012/Published online: 20 March 2013

(C) Crown Copyright 2013

\begin{abstract}
The majority of recent quarantine schedules have relied on methyl bromide fumigation. However, due to the phase-out of this fumigant in January 2005 alternative treatments are needed. Four alternative chemical fumigants were tested for their potential to replace methyl bromide as a control agent for Bemisia tabaci, Liriomyza huidobrensis and Frankliniella occidentalis. Phosphine at $2 \mathrm{~g} / \mathrm{m}^{3}$ gave promising results at $15{ }^{\circ} \mathrm{C}$ with complete mortality of all insects after $24 \mathrm{~h}$ exposure. Sulphuryl fluoride, ethyl formate and acetaldehyde caused severe damage to plant foliage after only $4 \mathrm{~h}$ exposure. However, sulphuryl fluoride produced $100 \%$ mortality of $L$. huidobrensis pupae after only $2 \mathrm{~h}$ exposure. In a large scale test using phosphine $2 \mathrm{~g} / \mathrm{m}^{3}$ at $15{ }^{\circ} \mathrm{C}$ complete mortality of L. huidobrensis eggs and pupae was recorded after a $24 \mathrm{~h}$ exposure. However, only 98.5 and $86 \%$ mortality of $B$. tabaci eggs and $F$. occidentalis eggs, respectively, was recorded after this treatment. Treatments with phosphine produced no significant detrimental effects on subsequent plant growth. The potential of these chemicals to act as alternatives to methyl bromide as quarantine fumigants is discussed.
\end{abstract}

Keywords Chemical control - Chrysanthemum . Fumigation · Methyl bromide $\cdot$ Quarantine

\footnotetext{
A. G. S. Cuthbertson $(\bowtie) \cdot$ K. Mills · T. Wonter-Smith • L. F. Blackburn - J. J. Mathers · P. Northing The Food and Environment Research Agency in York, Sand Hutton, York YO41 1LZ, England, UK e-mail: andrew.cuthbertson@fera.gsi.gov.uk
}

\section{Introduction}

The introduction of non-indigenous pests and diseases into a country can impact on both forestry and horticultural industries (Baker et al. 2000; McDonald et al. 1999), where crop damage and even complete loss may occur. Environmental damage has also been recorded following establishment of non-indigenous organisms (Murchie et al. 2003). The European Union (EU) identifies a range of organisms of plant health importance whose introduction and movement around the EU are prohibited (Bartlett 1993; Cheek and Cannon 2002). Therefore, effective disinfestation treatments are vital if traded plants and plant products are to meet these legislatory requirements. New pests and diseases, many of which show high levels of pesticide resistance, will further increase the prominence of these issues and the need for further pesticide use (Cahill et al. 1996; Ahmad et al. 2002; Cuthbertson and Brown 2009). This has resulted in the need for alternative means of pest control to be devised (Williams and Walters 2000; Kostyukovsky et al. 2002; Cuthbertson et al. 2003a, b, 2005a, b, 2008a, b, 2009a, b, 2012a; Giannakou and Karpouzas 2003).

The majority of recent quarantine schedules have relied on methyl bromide fumigation (Walters 2001). Methyl bromide is a critical element in the pre-plant management of soil-borne pests and pathogens in high value fruit, nursery and ornamental crops, and in post-harvest management of pests on fresh produce and durable commodities (Schneider et al. 2003). Since the early 1990s, this fumigant has been known to break down under the influence of strong UV rays, and thus release bromide atoms which deplete the ozone layer (WMO 1995; Dabrowski 2002). Increased awareness of the effect of chemicals on the environment and non-target organisms (Horowitz et al. 
2003; Cuthbertson and Murchie 2005, 2010, 2012) and the phase-out of methyl bromide in industrialised countries in January 2005 (Schneider et al. 2003) has lead to a greater demand for alternatives to methyl bromide for invertebrate pest control to be devised (Giannakou and Karpouzas 2003; Lopez-Aranda et al. 2003; Slusarski and Pietr 2003). Under current UK quarantine and pre-shipment rules methyl bromide can be used in an emergency situation if no viable alternative can be found.

A number of potential alternative treatments that may be suitable for quarantine disinfestation have been identified. These include; heat treatments, hot water treatments, composting, extreme controlled atmospheres and alternative fumigants (Walters 2001; Cuthbertson et al. 2009a). The aim of this study was to further investigate the use of phosphine and several natural plant volatiles as alternatives to methyl bromide for plant quarantine treatments against three plant pests; L. huidobrensis, Bemisia tabaci and $F$. occidentalis. For effective quarantine treatment $100 \%$ mortality of pest species was the objective of the study. The study was undertaken at The Food and Environment Research Agency (Fera), UK in 2005. The insects were maintained, under license, in the Plant Health Quarantine Entomology Laboratories at Fera.

\section{Materials and methods}

\section{Test fumigants}

The fumigants investigated were acetaldehyde, ethyl formate, sulphuryl fluoride and two formulations of phosphine (Frisin and Phostoxin tablets which produce phosphine in contact with atmospheric moisture along with small quantities of ammonia and carbon dioxide). These chemicals were chosen as preliminary tests had shown some potential for controlling the pests.

Concentrations of acetaldehyde were measured using Kitagawa gas detector tubes (tube number 133A). Other fumigant concentrations were measured using a Hewlett Packard 5890 series II gas chromatograph (GC) fitted with a flame photometric detector for phosphine and a thermal conductivity detector for ethyl formate and sulphuryl fluoride.

Fumigants were introduced into $1.7 \mathrm{~m}^{3}$ fumigation chambers at a concentration higher than the desired level. The concentration was measured and then reduced to the target concentration by partial evacuation of the chamber and the subsequent re-introduction of air.

The chambers were equipped with ports fitted with plastic sleeves that allowed test material to be introduced into the chambers and removed with minimal loss of concentration.
Insect cultures

Stock cultures of Bemisia tabaci, L. huidobrensis and F. occidentalis were maintained under quarantine conditions following the methods of Williams and Walters (2000) and McDonald et al. (1997), respectively, in perspex cages as described by Cuthbertson et al. (2003a).

The susceptibility of L. huidobrensis to alternative fumigants

Eggs

Batches of five 10-12 leaf chrysanthemum plants (Dendranthema morifolium c.v. White Fresco) were exposed within a separate perspex culture cage to 50-100 mixed sex L. huidobrensis adults, all of which were more than $24 \mathrm{~h}$ post-eclosion. After a $24 \mathrm{~h}$ egg-laying period, the flies were removed. The plants were then incubated with the various fumigant treatments in a fumigation chamber at $20^{\circ} \mathrm{C}$, $70 \%$ relative humidity (r.h.) with continuous lighting for $16,24,48$ or $72 \mathrm{~h}$. A control was incubated under normal atmospheric conditions. Following exposure, plants were incubated at $20{ }^{\circ} \mathrm{C}, 70 \%$ r.h. and a $16: 8 \mathrm{~h}$ light-dark regime until the assessment of mortality was conducted.

\section{Larvae}

As for egg infestation, chrysanthemum plants were exposed to 50-100 mixed sex L. huidobrensis adults, again within a separate culture cage, all of which were more than $24 \mathrm{~h}$ post-eclosion (Cuthbertson et al. 2009a). After a $24 \mathrm{~h}$ egglaying period, the flies were removed and the plants were incubated for 3 days at $22{ }^{\circ} \mathrm{C}, 65 \%$ r.h. prior to exposure to the various fumigants in order for the second instar stage to develop. The test plants were placed in the treatment chamber as described for L. huidobrensis eggs. Controls were incubated under normal atmospheric conditions. After exposure plants were returned to normal atmospheric conditions until the assessments of mortality were conducted.

\section{Pupae}

In initial tests with the fumigants, 20 pupae were placed into five ventilated glass vials with one vial exposed to each of the four treatments, and one control vial. In subsequent tests fifteen pupae were placed into each of 15 ventilated glass vials. Twelve of these vials were then exposed to the fumigant for $16,24,48$ or $72 \mathrm{~h}$ at $20^{\circ} \mathrm{C}$, $70 \%$ r.h. with continuous lighting. After exposure the vials were returned to normal atmospheric conditions until the assessments of mortality were conducted. A control group (3 vials) was incubated as described before. 
The susceptibility of $B$. tabaci to alternative fumigants

Eggs

Five chrysanthemum plants were each infested with two male and five female $B$. tabaci adults contained in clip cages (MacGillivray and Anderson 1957; Cuthbertson et al. 2003a). The plants were incubated for $48 \mathrm{~h}$ at $25^{\circ} \mathrm{C}, 70 \%$ r.h., 16:8 h L:D, after which the adult $B$. tabaci were removed. Four plants were then used in the fumigation trial with one as control. The control plant was kept at the same conditions as the treated plants in each trial but without the fumigant. This procedure was repeated for each fumigant tested. Following completion of the final exposure all plants were incubated for 7 days at $25{ }^{\circ} \mathrm{C}, 70 \%$ r.h., 16:8 h L:D. The number of eggs that hatched was recorded as a measure of survival of each treatment.

\section{Adults}

Fifteen adults were placed into each of 15 ventilated glass vials containing $10 \%$ non-bacterial agar and a $5 \mathrm{~cm}$ tomato leaf disc. Twelve of these vials were then exposed to each fumigant for the desired exposure periods. After exposure the vials were returned to the incubation chamber set at $65 \%$ r.h. and $20{ }^{\circ} \mathrm{C}$ and the assessments of mortality were conducted $24 \mathrm{~h}$ later. A control group (3 vials) was incubated under normal atmospheric conditions.

The susceptibility of $F$. occidentalis to alternative fumigants

\section{Eggs}

Six fine green beans were placed into an established culture of $F$. occidentalis for $24 \mathrm{~h}$. After this period the beans were removed from the culture, brushing any thrips back into the jar with a slim line paintbrush. The beans were then submersed in cold water for $10 \mathrm{~min}$ to ensure they are completely free of adult thrips and dried off with tissue paper. The beans were then split into two groups and placed within ventilated containers. One group acted as control and the other underwent treatment.

\section{Effect of fumigants on plant material}

Both rooted and unrooted chrysanthemum plants were obtained from a commercial source. During each fumigant trial an equal number (5) were treated with the fumigant and an equal number stored at $3{ }^{\circ} \mathrm{C}, 16: 8 \mathrm{~L}: \mathrm{D}$ as control. After the fumigation treatment both sets of cuttings were planted and grown on for 4 weeks, after which they were assessed quantitatively for wet and dry root and shoot growth along with shoot height. For the large scale testing of the most promising fumigant, five varieties of chrysanthemum (White Reagon, Lineker, Laredo, Stallion, Fontana) were chosen for testing. Again five plants were exposed to each fumigant with an equal number acting as control. After treatment, the cuttings were planted and grown on for 4 weeks, following which wet and dry shoot growth as well as shoot height was assessed.

\section{Results and discussion}

Fumigation is still one of the most effective methods for the protection of stored food, feed stuffs and other agricultural commodities from insect infestation (Kostyukovsky et al. 2002). The two main fumigants that are in use are methyl bromide and phosphine. Methyl bromide has been identified as a main contributor to ozone depletion (WMO 1995), and has now been phased out in developed countries except for quarantine and pre-shipment and for uses granted a critical use exemption. As for phosphine, there are increasing reports of chemical resistance of pests to this fumigant (Nakakita and Winks 1981; Tyler et al. 1983). The replacement of methyl bromide, classed as one of the most efficient soil fumigants, for the last 50 years (Giannakou and Karpouzas 2003) with alternative chemical treatments poses a major problem for the treating of many insect pest species and also quarantine insects in transit. The development of non-methyl bromide quarantine treatments will allow horticultural growers to eliminate the use of an environmentally damaging chemical while still protecting the industry from losses that could be caused by the introduction of new pests and diseases (Cuthbertson et al. 2009a, $2012 a, b)$.

Experiment 1: exposure to phosphine, 1 and $2 \mathrm{~g} / \mathrm{m}^{3}$ (as Frisin and Phostoxin tablets) at $20^{\circ} \mathrm{C}$ for 6,16 , 24 and $48 \mathrm{~h}$

After all three phosphine treatments (Phostoxin tablets $2 \mathrm{~g} / \mathrm{m}^{3}$; Frisin $2 \mathrm{~g} / \mathrm{m}^{3}$; Frisin $1 \mathrm{~g} / \mathrm{m}^{3}$ ), $100 \%$ mortality was recorded for all species and life stages following exposures lasting $16 \mathrm{~h}$ or longer, with the exception of one $L$. $h u$ idobrensis egg and two of sixty B. tabaci eggs following treatment with Frisin at $2 \mathrm{~g} / \mathrm{m}^{3}$ at $20{ }^{\circ} \mathrm{C}$ (Fig. 1). Bemisia tabaci adults were less tolerant to phosphine and all were killed by the $6 \mathrm{~h}$ exposures. The $6 \mathrm{~h}$ exposures did not achieve complete mortality of the L. huidobrensis life stages and different formulations resulted in similar levels of mortality.

The treated leaves of unrooted cuttings displayed more discolouration (yellowing) than untreated controls. 
Additionally the oldest leaves exhibited necrotic brown patches that increased in size with the duration of the exposure to phosphine at $2 \mathrm{gm} / \mathrm{m}^{3}$. The apical buds showed no visible damage and the subsequent growth and general appearance of the plants was normal following exposures up to $24 \mathrm{~h}$. Exposures greater than this killed the plants. Plant height and dry weights of shoots and roots generally decreased with an increase in exposure (Fig. 2).

Experiment 2: exposure to phosphine (as Frisen) $2 \mathrm{~g} / \mathrm{m}^{3}$ at $15^{\circ} \mathrm{C}$

Complete mortality of B. tabaci eggs occurred after $24 \mathrm{~h}$ exposure. Liriomyza huidobrensis larvae and pupae were also killed after 16 and 24 h, respectively (Fig. 3). Similar plant effects were recorded in this treatment as were obtained by the same treatment at $20{ }^{\circ} \mathrm{C}$. Damage symptoms included yellow and pale green leaf patches, the size of which increased with the duration of exposure to the modified atmosphere. Shoot height generally decreased with exposure time (Fig. 4).

Experiment 3: exposure to phosphine $4 \mathrm{~g} / \mathrm{m}^{3}$ at $15{ }^{\circ} \mathrm{C}$

Complete mortality of L. huidobrensis pupae and eggs was recorded after a $24 \mathrm{~h}$ exposure to this high dose (Fig. 5). Almost complete mortality of $B$. tabaci eggs was achieved. An observational test of three dwarf bean pods infested with $F$. occidentalis eggs did not prove successful; a small
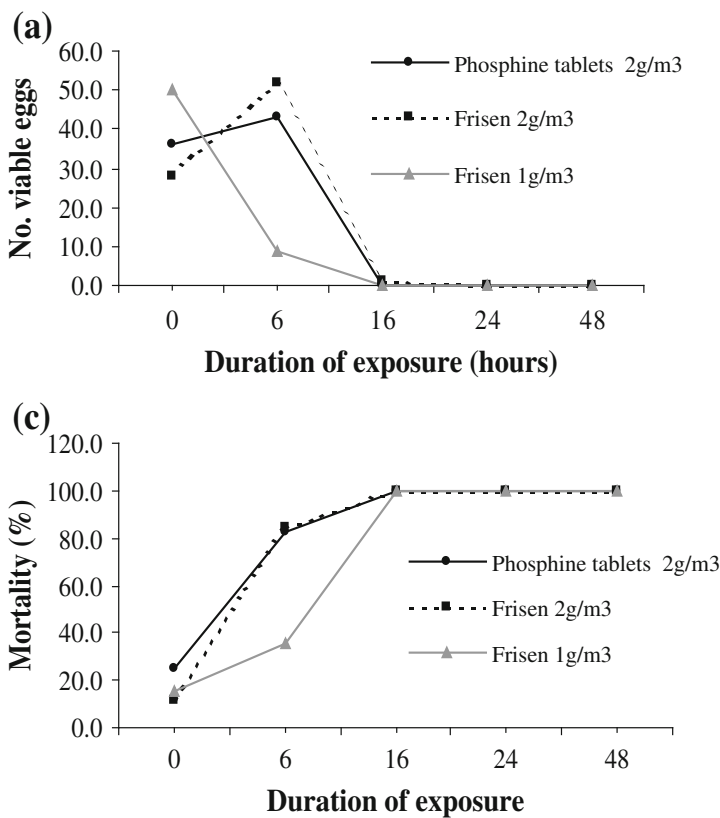

number of eggs survived the treatment and successfully developed to larval stage. No plant measurements were taken in this trial.

Experiment 4: result of exposure to phosphine $2 \mathrm{~g} / \mathrm{m}^{3}$ at $10{ }^{\circ} \mathrm{C}$

All B. tabaci eggs were killed after a $24 \mathrm{~h}$ exposure period. Complete mortality of $L$. huidobrensis pupae and eggs was recorded after a $16 \mathrm{~h}$ exposure (Fig. 6). Following a $16 \mathrm{~h}$ exposure approximately $50 \%$ of leaves on the plants were dead. Four weeks after treatment mean shoot height was not significantly different compared to the untreated control after $16 \mathrm{~h}$ exposure. However, the longer exposures of 24 and $48 \mathrm{~h}$ did effect shoot growth. Dry shoot and root weights were reduced by the treatment with significant decreases in root and shoot dry weights of plants exposed to phosphine for $24 \mathrm{~h}$ (Fig. 7).

The general levels of pest control recorded in this study following phosphine at $20{ }^{\circ} \mathrm{C}$ were promising. The phosphine treatments did not appear to be damaging to the host plants and the treatment following $6 \mathrm{~h}$ exposure had no detrimental effect on the subsequent root and shoot growth of treated unrooted cuttings (Cuthbertson A.G.S., pers. $o b s$.). In addition, it may be feasible to use this treatment with other plant species that are more tolerant to the fumigant. Subsequent treatments with phosphine at the lower temperature of $15{ }^{\circ} \mathrm{C}$ resulted in complete mortality of all insect stages tested after $24 \mathrm{~h}$, and as a result this $24 \mathrm{~h}$ treatment was selected for large scale testing. This

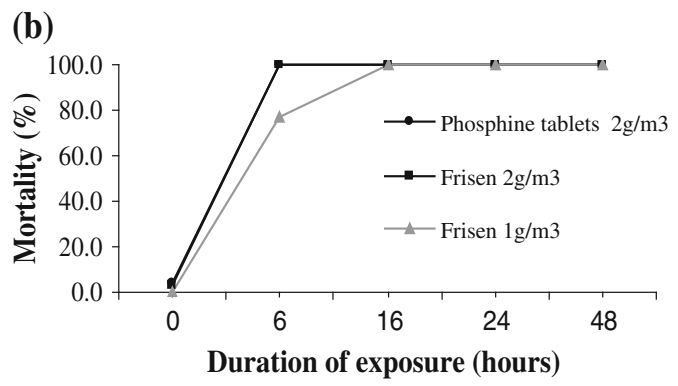

(d)

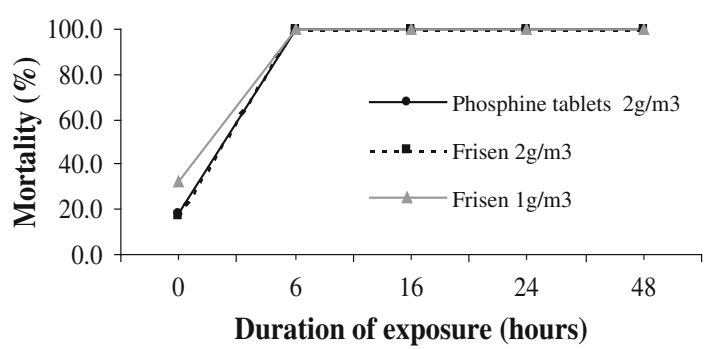

Fig. 1 The effect of exposure to three phosphine treatments at $20^{\circ} \mathrm{C}$ on (a) L. huidobrensis eggs, (b) L. huidobrensis larvae, (c) L. huidobrensis pupae, and (d) Bemisia tabaci adults 

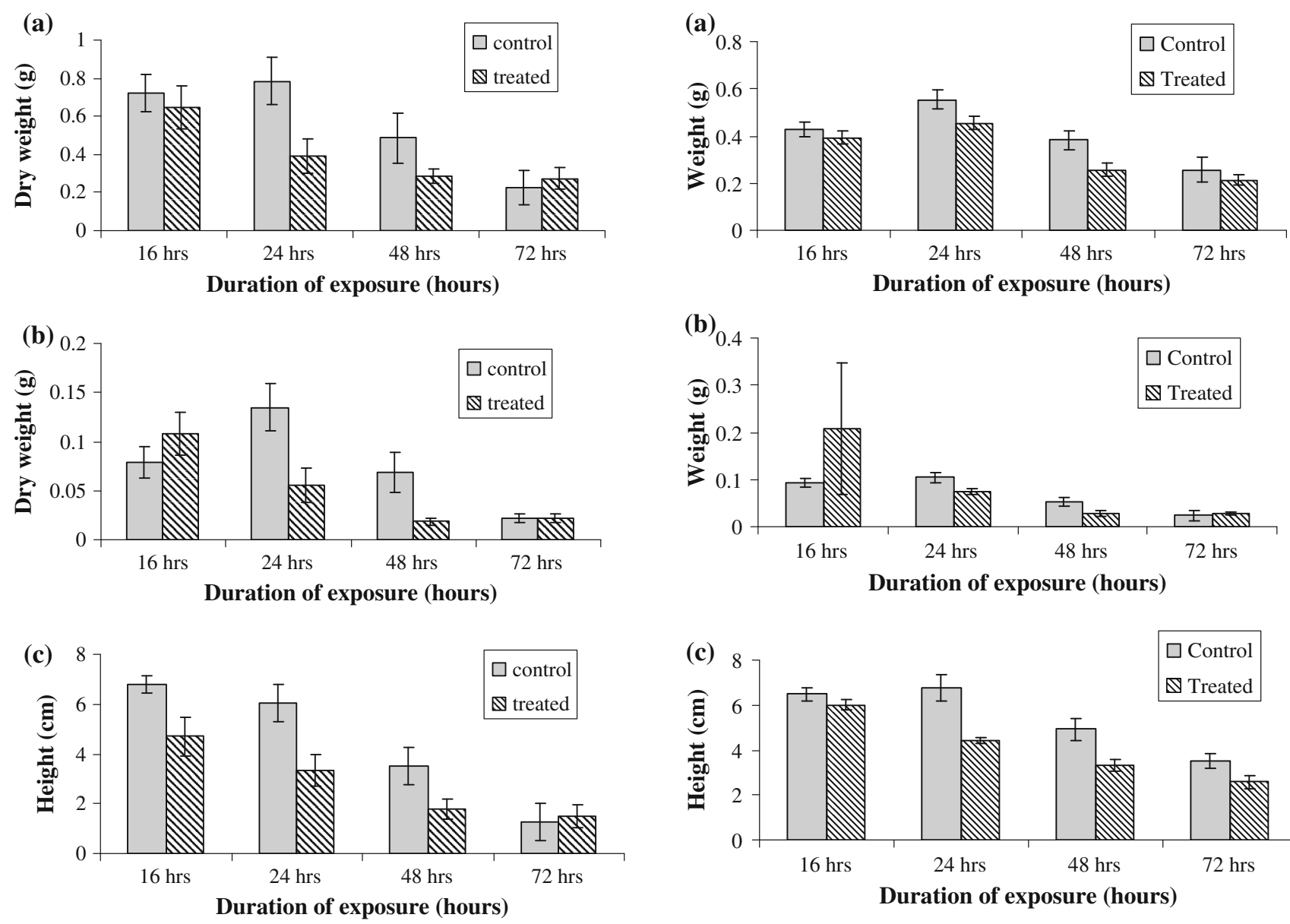

Fig. 2 a-c Dry shoot weight, root weight and shoot height of chrysanthemum plants $(N=5)$ after phosphine treatment at $2 \mathrm{~g} / \mathrm{m}^{3}$ at $20{ }^{\circ} \mathrm{C}$

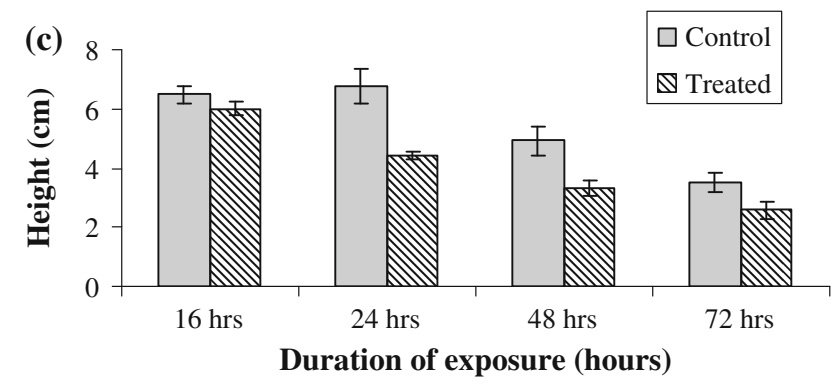

Fig. 4 a-c Dry shoot weight, root weight and shoot height of chrysanthemum plants $(N=5)$ after phosphine treatment at $2 \mathrm{~g} / \mathrm{m}^{3}$ at $15{ }^{\circ} \mathrm{C}$

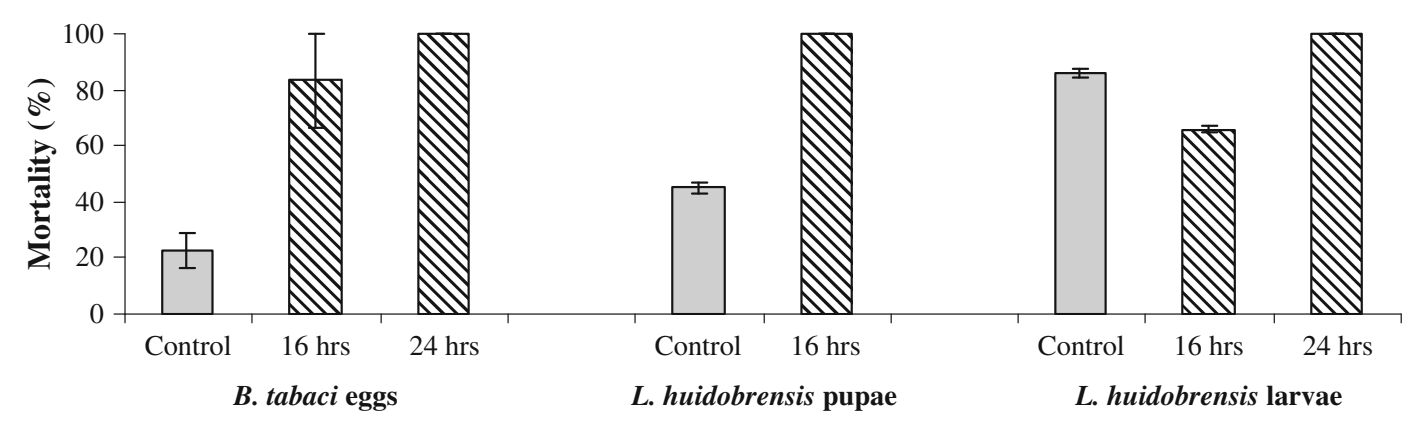

Duration of exposure (hours)

Fig. 3 Effect of $2 \mathrm{~g} / \mathrm{m}^{3}$ of phosphine at $15{ }^{\circ} \mathrm{C}, 70 \%$ r.h and under constant light conditions on Bemisia tabaci eggs and Liriomyza huidobrensis pupae and larvae

treatment killed all the $L$. huidobrensis eggs and pupae, however, some B. tabaci and F. occidentalis eggs survived to hatch into larvae. In the small-scale tests some $F$. occidentalis eggs survived exposure to twice the dose of phosphine for a $24 \mathrm{~h}$ period. The results indicate just how difficult it is to treat against these cryptic pests using these exposure periods.
Experiment 5: result of exposure to sulphuryl fluoride (as Vikane) $20 \mathrm{~g} / \mathrm{m}^{3}$ at $15{ }^{\circ} \mathrm{C}, 70 \%$ r.h. (exposure times $2,4,6,8,16,24,48$, and $72 \mathrm{~h}$ )

All plants were killed after exposure to sulphuryl fluoride for $4 \mathrm{~h}$ or longer. Fifty percent of the leaves on treated plants were killed after only $2 \mathrm{~h}$ exposure. As a result the 
Fig. 5 Effect of $4 \mathrm{~g} / \mathrm{m}^{3}$ of phosphine at $15{ }^{\circ} \mathrm{C}, 70 \%$ r.h and under constant light conditions on Bemisia tabaci eggs and Liriomyza huidobrensis pupae and eggs

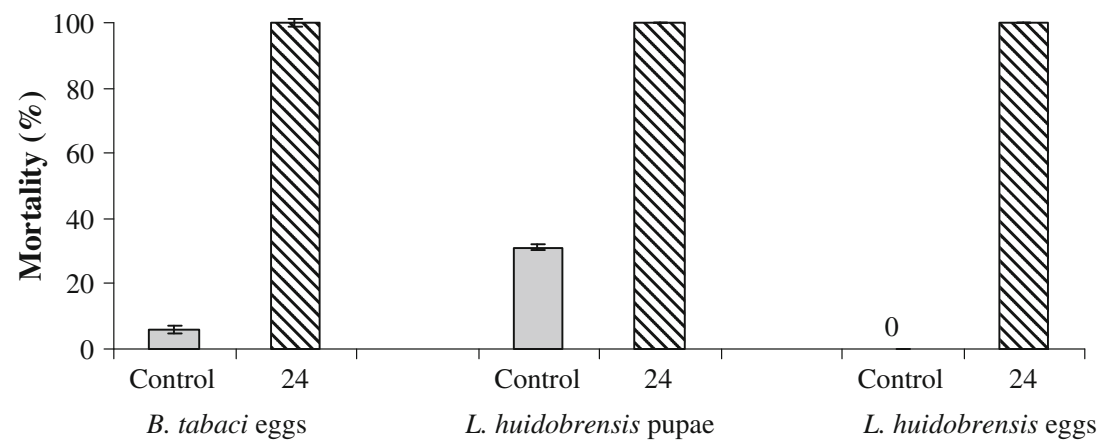

Duration of exposure (hours)

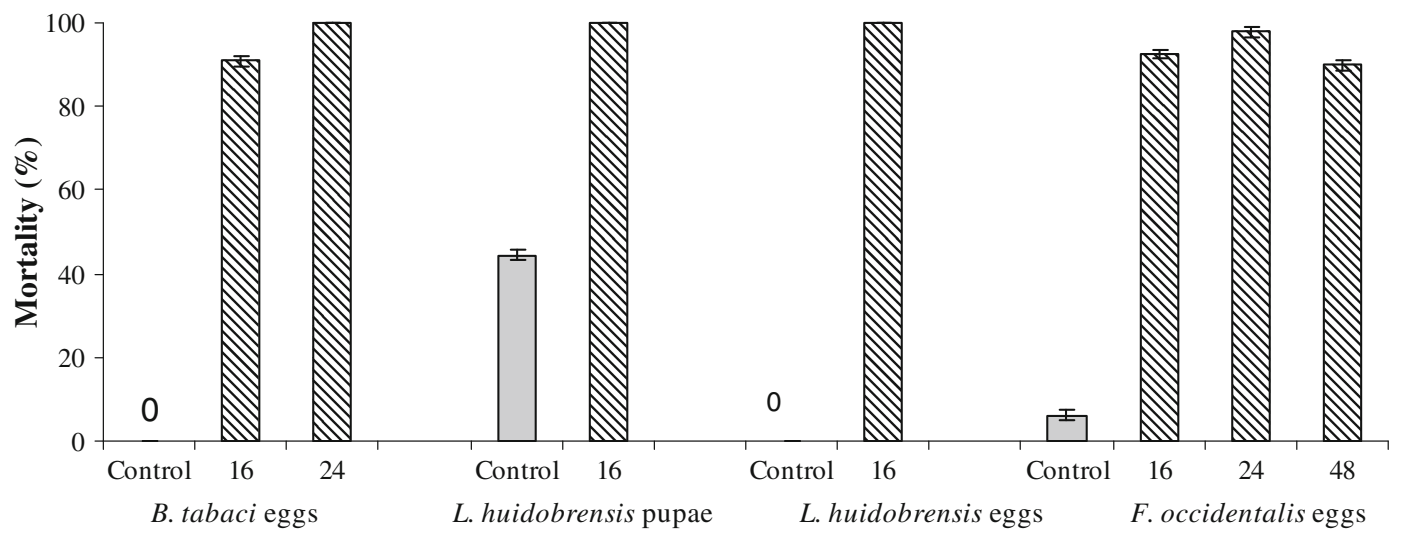

Duration of exposure (hours)

Fig. 6 Effect of $2 \mathrm{~g} / \mathrm{m}^{3}$ of phosphine at $10{ }^{\circ} \mathrm{C}, 70 \%$ r.h. and under constant light conditions on Bemisia tabaci and Frankliniella occidentalis eggs and Liriomyza huidobrensis pupae and eggs

B. tabaci or L. huidobrensis eggs attached to or within the plant material were also non-viable. Total mortality of L. huidobrensis pupae was obtained after a $2 \mathrm{~h}$ exposure to the fumigant. No shoot or root weights were recorded due to severe plant damage.

Experiment 6: result of exposure to acetaldehyde $10 \mathrm{~g} / \mathrm{m}^{3}$ at $15{ }^{\circ} \mathrm{C}$

Due to severe plant damage, no live L. huidobrensis eggs were recorded in the treated plants. Complete control of B. tabaci eggs was obtained after $4 \mathrm{~h}$ exposure. Importantly this treatment had little effect on L. huidobrensis pupae with a maximum of only $25 \%$ mortality resulting from any of the treatments (Fig. 8). This was not significantly different $(P>0.005)$ to the level of natural mortality observed in the control group. Plants were badly damaged after $4 \mathrm{~h}$ exposure to acetaldehyde with over half of the leaves recorded as dead. Dry shoot and root weights decreased with exposure time whereas shoot height appeared to be unaffected by exposures of $24 \mathrm{~h}$ or less (Fig. 9).
Experiment 7: result of exposure to ethyl formate $85 \mathrm{~g} / \mathrm{m}^{3}$ at $15^{\circ} \mathrm{C}$

All plants exposed to this treatment were also severely damaged and therefore it was not possible to assess the effect on survival of $B$. tabaci or L. huidobrensis eggs. However, as L. huidobrensis pupae are not dependent on survival of the plant material it was possible to determine the effect of the treatment. After a $3.5 \mathrm{~h}$ exposure to ethyl formate $95 \%$ mortality of L. huidobrensis pupae was recorded. Due to the severe burning of leaves no dry weights or shoot heights were recorded.

Tests with the other fumigants (sulphuryl fluoride, acetaldehyde, ethyl formate) showed less potential for development as quarantine treatments primarily due to the severe damage caused to the plant material. Sulphuryl fluoride caused $50 \%$ mortality of plants after $2 \mathrm{~h}$ exposure and severe damage to all plants treated for $4 \mathrm{~h}$ or longer, as a result it was not possible to assess the effect of the fumigant on the insect egg stages attached or within the leaf material. However, the fumigant was very effective at killing leaf-miner pupae with $100 \%$ mortality occurring 

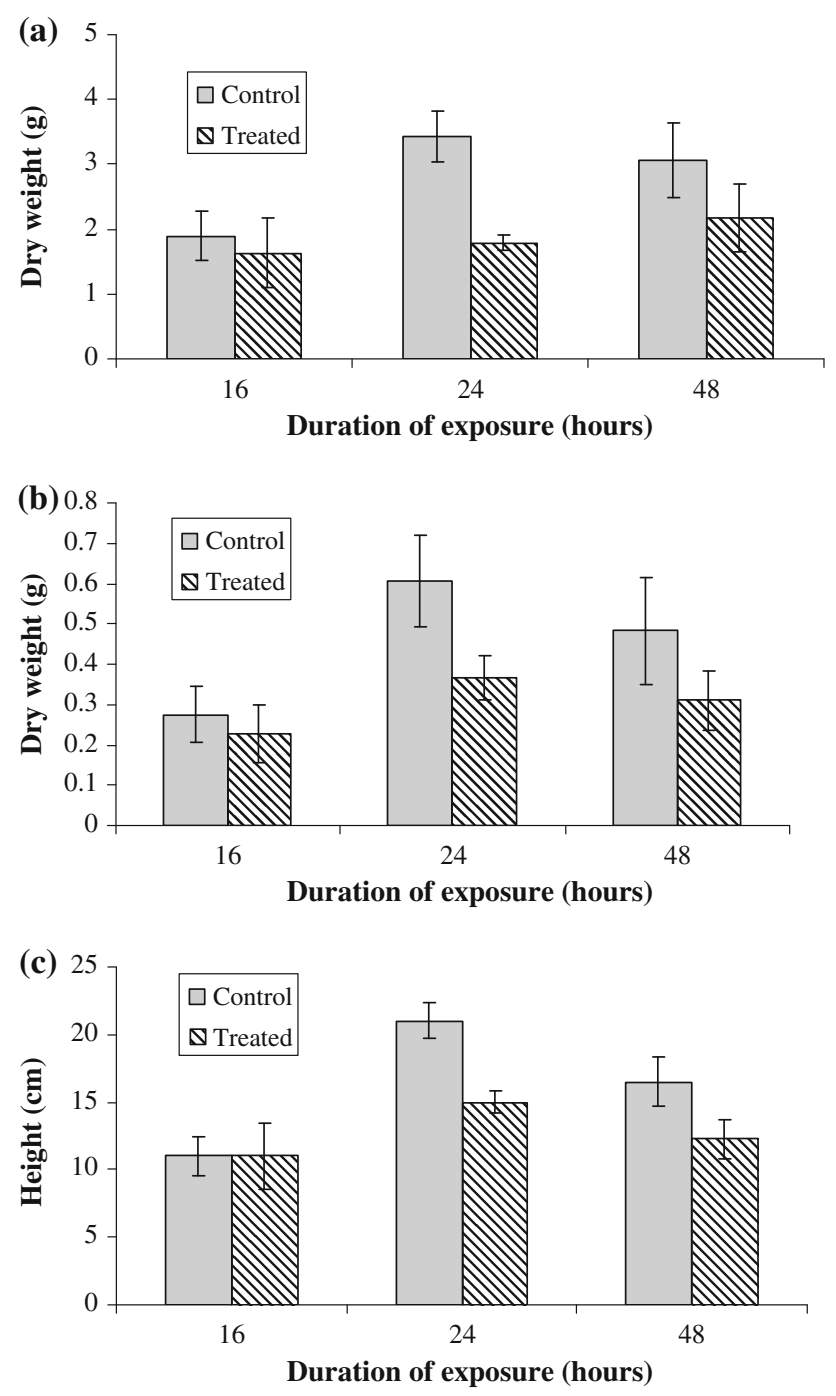

Fig. 7 a-c Dry shoot weight, root weight and shoot height of chrysanthemum plants after phosphine treatment at $2 \mathrm{~g} / \mathrm{m}^{3}$ at $10{ }^{\circ} \mathrm{C}$

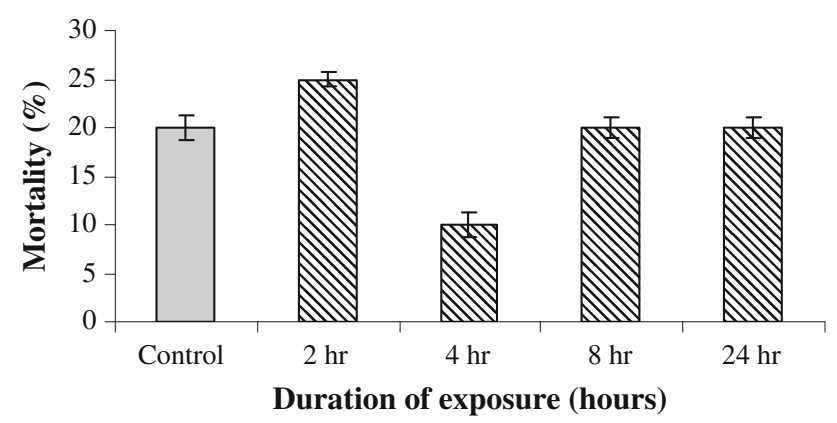

Fig. 8 Effect of an exposure of $10 \mathrm{~g} / \mathrm{m}^{3}$ of acetaldehyde at $15^{\circ} \mathrm{C}$ on L. huidobrensis pupae

following a $2 \mathrm{~h}$ exposure. Similarly, ethyl formate also caused severe damage to the plant material, again rendering assessments of egg survival impossible. However, the
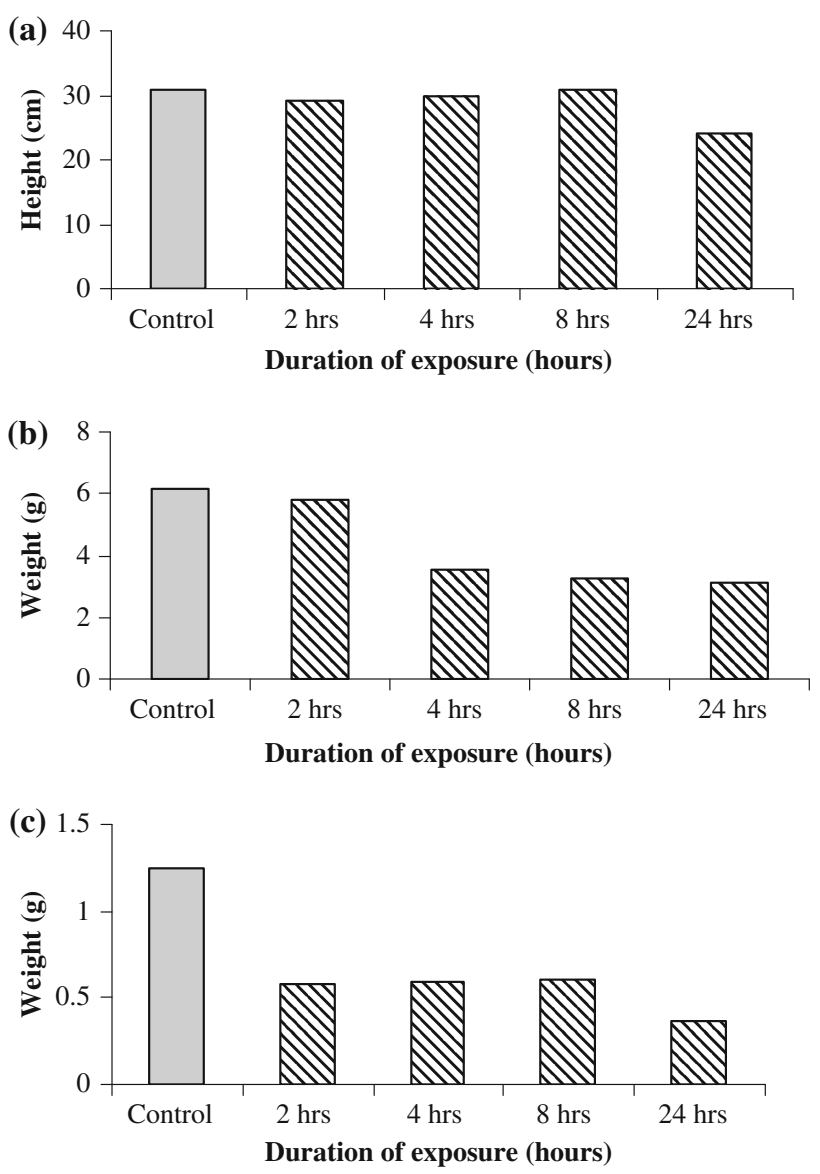

Fig. 9 a-c Dry shoot weight, root weight and shoot height of chrysanthemum plants after treatment to $10 \mathrm{~g} / \mathrm{m}^{3}$ of acetaldehyde at $15{ }^{\circ} \mathrm{C}$

effect on leaf-miner pupae was high with $95 \%$ mortality obtained after a $3.5 \mathrm{~h}$ exposure.

Experiment 8: result of large scale testing (test fumigant phosphine $2 \mathrm{~g} / \mathrm{m}^{3}$ at $15^{\circ} \mathrm{C}$ )

A total of 3,189 insects were exposed to the fumigant. Complete mortality of both $L$. huidobrensis pupae and eggs was recorded after the $24 \mathrm{~h}$ exposure. However, only 98.5 and $86 \%$ mortality of $B$. tabaci and F. occidentalis, respectively, was achieved (Fig. 10). Immediately after a $24 \mathrm{~h}$ exposure, all plant material appeared healthy with no signs of damage. No significant decrease in dry weights of shoots or roots was noted in any of the varieties. Mean plant height also remained similar to the untreated control after the 4-week growth period (Fig. 11).

The exposure of chrysanthemum rooted plants and unrooted cuttings to the various formulations and doses of fumigants resulted in varying degrees of plant damage. The fumigants sulphuryl fluoride, ethyl formate and acetaldehyde appear to be of little value as the plants were killed 
Fig. 10 Large scale assessment of the effect of $2 \mathrm{~g} / \mathrm{m}^{3}$ of phosphine at $15{ }^{\circ} \mathrm{C}$, $70 \%$ r.h. and under constant light conditions on Bemisia tabaci and Frankliniella occidentalis eggs and Liriomyza huidobrensis pupae and eggs
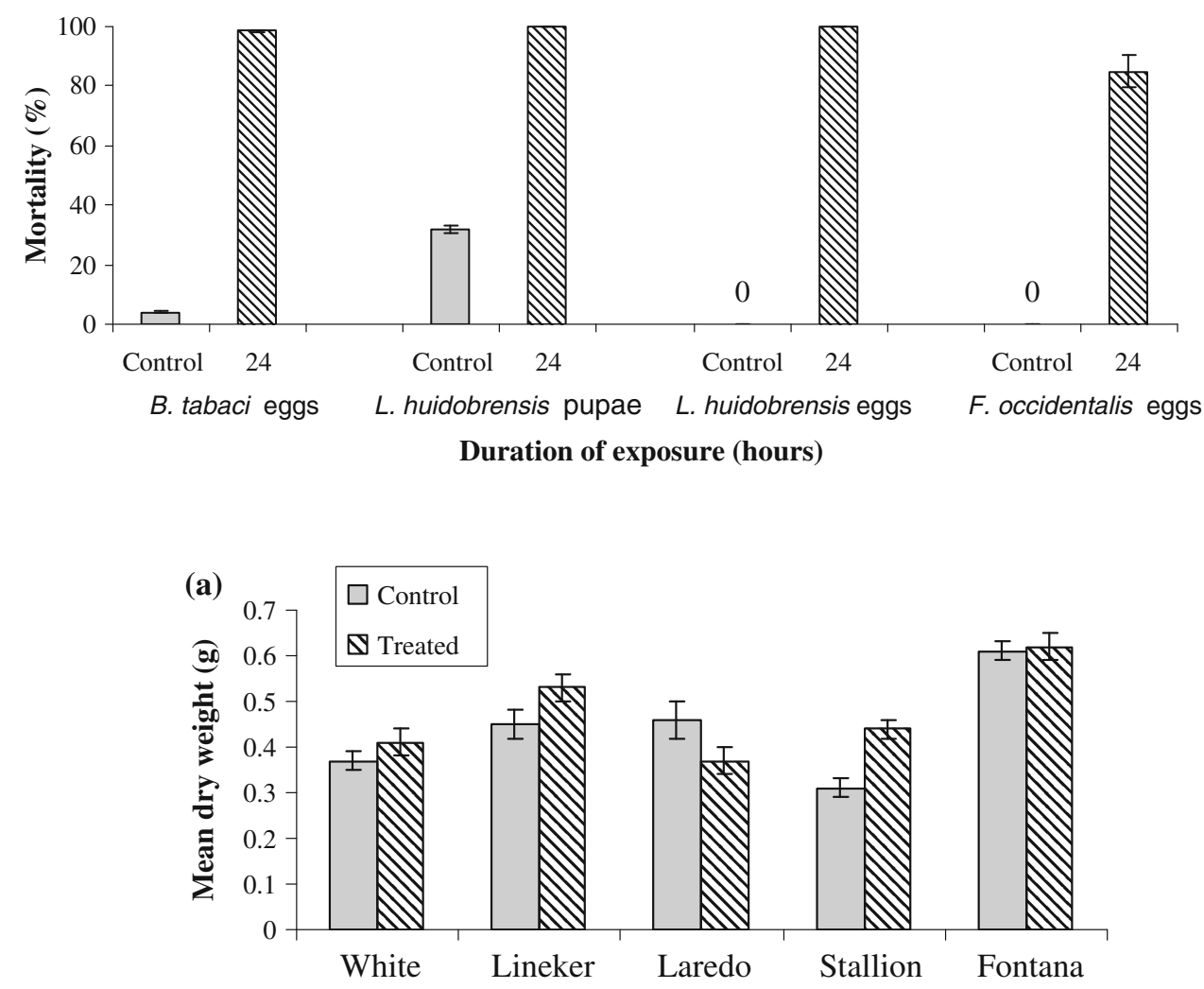

Reagon

\section{Chrysanthemum variety}

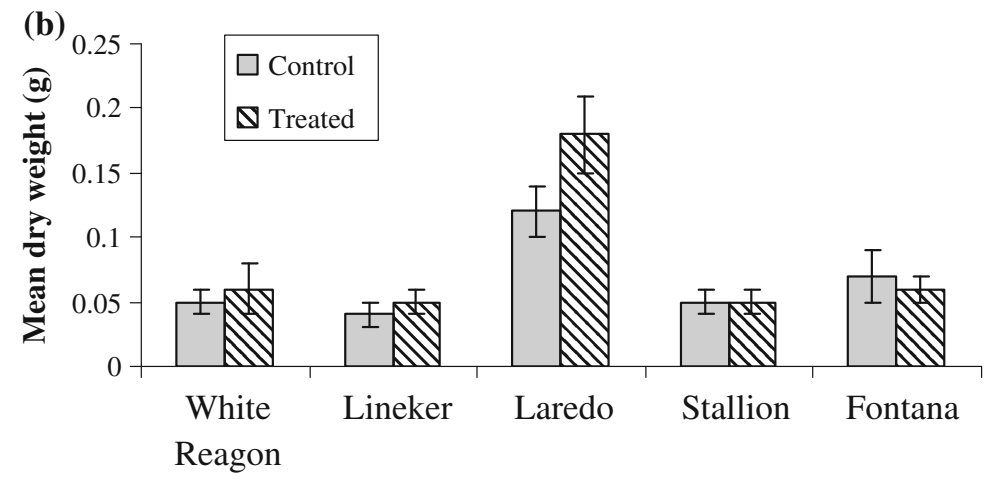

Chrysanthemum variety

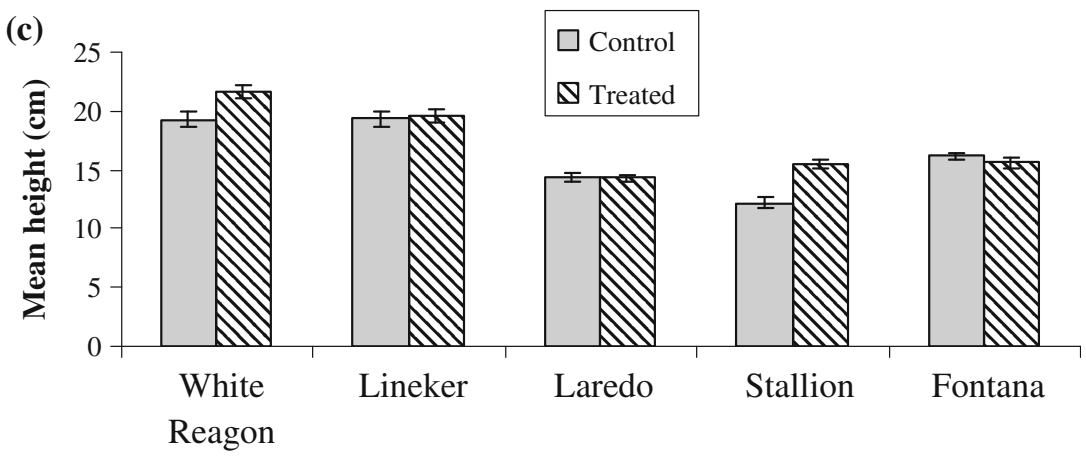

Chrysanthemum variety 
even after short exposure times. In treatments using phosphine, any detrimental effects on the plants' subsequent growth and appearance were not as pronounced as some of the other treatments. Exposure to an atmosphere of $2 \mathrm{~g} / \mathrm{m}^{3}$ of phosphine for as long as $16 \mathrm{~h}$ (at 15 or $20^{\circ} \mathrm{C}$ ) appeared to have little effect on subsequent plant growth. Treatments for commercial use must achieve good insect pest control without causing unacceptable damage to the associated plant material.

\section{Conclusion}

Phosphine would appear to have the most potential for development of a quarantine fumigant out of the possible chemicals investigated. The treatment temperature and duration both need to be kept to a minimum to limit plant damage whilst high levels of pest mortality are obtained. The combination of chemical fumigants with other possibilities such as essential oil extracts from aromatic plants (Kostyukovsky et al. 2002) may provide the answer in the search for alternatives to methyl bromide for the fumigation of quarantine pests in transit.

Acknowledgments The work formed part of EC funded project FAIR CT98 4259.

\section{References}

Ahmad M, Arif MI, Ahmad Z, Denholm I (2002) Cotton whitefly (Bemisia tabaci) resistance to organophosphate and pyrethroid insecticides in Pakistan. Pest Manag Sci 58(2):203-208

Baker RHA, Sanford CE, Jarvis CH, Cannon RJC, MacLeod A, Walters KFA (2000) The role of climatic mapping in predicting the potential geographical distribution of non-indigenous pests under current and future climates. Agri Eco Environ 82(1-3): $57-71$

Bartlett PW (1993) Plant quarantine experience of Liriomyza spp. in England and Wales. Liriomyza conference on leaf mining flies in cultivated plants. Montpellier, 1(1):23-30

Cahill M, Gorman K, Day S, Denholm I, Elbert A, Nauen R (1996) Baseline determination and detection of resistance to imidacloprid in Bemisia tabaci (Homoptera: Aleyrodidae). Bull Entomol Res 86(4):343-349

Cheek S, Cannon RJC (2002) Alien pests: opportunities and risks for biological control. BCPC Conf Pests Dis 1(1):97-102

Cuthbertson AGS, Brown MA (2009) Issues affecting British honey bee biodiversity and the need for conservation of this important ecological component. Int J Environ Sci Tech 6(4):695-699

Cuthbertson AGS, Murchie AK (2005) European red spider mite-an environmental consequence of persistent chemical pesticide application. Int J Environ Sci Tech 2(3):287-290

Cuthbertson AGS, Murchie AK (2010) Ecological benefits of Anystis baccarum in an orchard ecosystem and the need for its conservation. Int J Environ Sci Tech 7(4):807-813

Cuthbertson AGS, Murchie AK (2012) Anystis baccarum-a predatory mite in UK apple orchards. Res $\mathrm{J}$ Chem Environ 16(1):18-21
Cuthbertson AGS, Head J, Walters KFA, Gregory SA (2003a) The efficacy of the entomopathogenic nematode, Steinernema feltiae, against the immature stages of Bemisia tabaci. J Invertebr Pathol 83(3):267-269

Cuthbertson AGS, Head J, Walters KFA, Murray AWA (2003b) The integrated use of chemical insecticides and the entomopathogenic nematode, Steinernema feltiae, for the control of sweet potato whitefly Bemisia tabaci. Nematology 5(5):713-720

Cuthbertson AGS, Walters KFA, Northing P (2005a) The susceptibility of immature stages of Bemisia tabaci to the entomopathogenic fungus Lecanicillium muscarium on tomato and verbena foliage. Mycopathologia 159(1):23-29

Cuthbertson AGS, Walters KFA, Deppe C (2005b) Compatibility of the entomopathogenic fungus Lecanicillium muscarium and insecticides for eradication of sweet potato whitefly Bemisia tabaci. Mycopathologia 160(1):35-41

Cuthbertson AGS, Blackburn LF, Northing P, Luo W, Cannon RJC, Walters KFA (2008a) Further compatibility tests of the entomopathogenic fungus Lecanicillium muscarium with conventional insecticide products for control of sweet potato whitefly, Bemisia tabaci on poinsettia plants. Insect Sci 15(4):355-360

Cuthbertson AGS, Mathers JJ, Northing P, Prickett AJ, Walters KFA (2008b) The integrated use of chemical insecticides and the entomopathogenic nematode, Steinernema carpocapsae (Nematoda: Steinernematidae), for the control of sweet potato whitefly, Bemisia tabaci (Hemiptera: Aleyrodidae). Insect Sci 15(5): $447-453$

Cuthbertson AGS, Blackburn LF, Northing P, Mathers JJ, Luo W, Walters KFA (2009a) Environmental evaluation of hot water treatments to control Liriomyza huidobrensis infesting plant material in transit. Int. J. Environ. Sci. Tech. 6(2):167-174

Cuthbertson AGS, Blackburn LF, Northing P, Luo W, Cannon RJC, Walters KFA (2009b) Leaf dipping as an environmental screening measure to test chemical efficacy against Bemisia tabaci on poinsettia plants. Int J Environ Sci Tech 6(3):347-352

Cuthbertson AGS, Buxton JH, Blackburn LF, Mathers JJ, Robinson K, Powell ME, Fleming DA, Bell HA (2012a) Eradicating Bemisia tabaci $\mathrm{Q}$ on poinsettia plants in the UK. Crop Prot 42(1):42-48

Cuthbertson AGS, Mathers JJ, Blackburn LF, Powell ME, Marris G, Pietravalle S, Brown MA, Budge GE (2012b) Screening commercially available entomopathogenic biocontrol agents for the control of Aethina tumida (Coleoptera: Nitidulidae) in the UK. Insects 3(3):719-726

Dabrowski ZT (2002) Alternatives to methyl bromide in protection against storage pests. Ochrona Roslin 46(1):12-14

Giannakou IO, Karpouzas DG (2003) Evaluation of chemical and integrated strategies as alternatives to methyl bromide for the control of root-knot nematodes in Greece. Pest Manag Sci 59(8):883-892

Horowitz AR, Gorman K, Ross G, Denholm I (2003) Inheritance of pyriproxyfen resistance in the whitefly, Bemisia tabaci (Q biotype). Arch Ins Biochem Physiol 54(4):177-186

Kostyukovsky M, Ravid U, Shaaya E (2002) The potential use of plant volatiles for the control of stored product insects and quarantine pests in cut flowers. Acta Hort 576(1):347-358

Lopez-Aranda JM, Medina JJ, Miranda L, Montes F, Romero F, Vega JM, Paez JI, Los Santos B, de Dominguez F, Lopez-Medina J, Flores F, Clavero I, Galvez J, Becerril M, Palacios J, Bardon E, Martinez-Beringola ML, Salto T, Cal A, Martinez-Treceno A, Melgarejo P (2003) Alternatives to methyl bromide: Spanish trials. Colture Protette 32(1):59-65

MacGillivray MF, Anderson GB (1957) Three useful insect cages. Can Entomol 89(1):43-46

McDonald JR, Bale JS, Walters KFA (1997) Low temperature mortality and overwintering of the western flower thrips 
Frankliniella occidentalis (Thysanoptera: thripidae). Bull Entomol Res 87(5):497-505

McDonald JR, Bale JS, Walters KFA (1999) Temperature development and establishment potential of Thrips palmi in the UK. Euro J Entomol 95(2):169-173

Murchie AK, Moore JP, Walters KFA, Blackshaw RP (2003) Invasion of agricultural land by the earthworm predator, Arthurdendyus triangulatus (Dendy). Pedobiologia 47(5-6): 920-923

Nakakita H, Winks RG (1981) Phosphine resistance in immature stages of a laboratory selected strain of Tribolium castaneum (Herbst). J Stored Prod Res 17(2):43-52

Schneider SM, Rosskopf EN, Leesch JG, Chellemi DO, Bull CT, Mazzola M (2003) United States Department of Agriculture-Agricultural Research Service research on alternatives to methyl bromide: pre-plant and post-harvest. Pest Manag Sci 59(6-7):814-826
Slusarski C, Pietr SJ (2003) Validation of chemical and non-chemical treatments as methyl bromide replacements in field grown cabbage, celeriac and tomato. Veg Crops Res Bull 58(1): $113-126$

Tyler PS, Taylor RW, Rees DP (1983) Insect resistance to phosphine fumigation in food warehouses in Bangladesh. Int Pest Contr 25(1):10-13

Walters KFA (2001) Phytosanitary alternatives to Methyl Bromide in Europe. NAPPO Bulletin 16(1):21-26

Williams EC, Walters KFA (2000) Foliar application of the entomopathogenic nematode, Steinernema feltiae against leafminers on vegetables. Biocontr Sci Technol 10(1):61-70

WMO (1995) Scientific assessment of ozone depletion: World Meteorological Organization global ozone research and monitoring project, Report no. 37, WMO, Geneva, Switzerland 